\title{
Optimization of regeneration technology on an energy crop- castor (Ricinus communis, L.)
}

\author{
Wei $\mathrm{Li}^{1,2}$, Yujia Zhai ${ }^{1}$, Guixian Yang ${ }^{1}$, Zhenjing $\mathrm{Li}^{1}$, Changlu Wang ${ }^{1}$ \\ ${ }^{1}$ School of Food Engineering and Biotechnology, Tianjin University of Science and Technology, \\ Tianjin, 300457, China \\ ${ }^{2}$ College of Biology Science and Engineering (Hebei University of Economics and Business), \\ Shijiazhuang, Hebei, 050061, China
}

Keywords: Castor, Embryogenic tissues, Regeneration.

\begin{abstract}
An efficient regeneration protocol for in vitro propagation of castor through embryonic tips was developed. According to the different properties of seed germination and embryo germination, 5 explants with high regeneration ability were picked out and their stress abilities in pre-culture period were compared. Effect on bud induction of different cytokinins (BA/TDZ/ZT) and auxin (IBA) was studied. The optimal bud induction medium was MSB5 with $0.35 \mathrm{mg} / \mathrm{L}$ BA and $0.25 \mathrm{mg} / \mathrm{L}$ IBA. The rooting and transplanting stage were also optimized and transplant survival rate was improved. The final regeneration efficiency can reach $68.3 \%$.
\end{abstract}

\section{Introduction}

Castor (Ricinus Communis. L), a kind of important industrial oil crops, is one of the top ten oil crops in the world which has high economic value and a wide range of industrial applications [1]. More than 3000 kinds of chemical derivatives have been developed and applied in the fileds such as national defense, aviation, aerospace, chemical medicine and machinery manufacturing, etc [2]. Thus the castor industry is considered to be promising resulting from wide applications and culturing castor varieties with good quality and high yield are becoming the research hotspot.

Molecular breeding technique has many advantages compared with conventional method. Therefore, molecular breeding technique is tried to apply on castor breeding gradually. In 1988, Sujatha built castor regeneration system for the first time successfully [3].On the basis of this, Sujatha and Sailaja implemented castor transformation successfully with the application of agrobacterium and gene gun mediated method in 2005 and 2008 respectively. But the conversion rate is low and unstable [4,5]. In addition, taking cotyledon section and cotyledon as explants respectively, ahn built castor regeneration system and obtained the good results [6]. Difficulty of castor regeneration is still the primary issue in the development of plant molecular breeding. In the current research of plant regeneration system, the selection of the explant is various. As the starting point of the regeneration process, the difference of explant is also the key factors influencing the regeneration efficiency. On the basis of predecessors, this study through the embryo germination and seed germination, different explants are selected for regeneration induction to screen out the most suitable explant, build a stable regeneration system, and lay the foundation for implementation of castor molecular breeding.

\section{Materials and methods}

\section{Plant material}

Mature castor seeds were collected from Shandong Jiaxiang Castor Research Centre. Seeds were decoated and immerged in $0.1 \% \mathrm{KMnO} 4$ solution for 10 min for sterilization, then cleaned with sterile water for 2-3 times.

\section{Selection of explants}

Explant selection is based on two types of germination. Seed germination: will be disinfected seeds were plant on MS medium of $0-0.5 \mathrm{mg} / \mathrm{L} \mathrm{BA}, 28{ }^{\circ} \mathrm{C}$, the dark condition; When the cotyledon 
opened, taking cotyledon, cotyledonary node and hypocotyl as explants, plant them on MS culture medium with $0.2 \mathrm{mg} / \mathrm{L} \mathrm{BA}$, observing the growth of explants. Embryo germination method: split disinfected seeds carefully with forceps, take the embryo and plant it on MS medium containing 0$0.5 \mathrm{mg} / \mathrm{L} \mathrm{BA}, 28{ }^{\circ} \mathrm{C}$, in dark conditions; when the embryo grew to 4-6 mm, take its embryonic tips and hypocotyl as explants, plant them on MS culture medium with $0.2 \mathrm{mg} / \mathrm{L} \mathrm{BA}$, observing the growth.

\section{Sprout induction}

Three kind of cytokinin, BA(0.2,0.35,0.5,1 mg/L), TDZ(0.05,0.1,0.2,0.4 mg/L),ZT(4,6,8,10mg/L), were selected to induce sprouts. Pant proper explants on medium with different cytokinins, $28{ }^{\circ} \mathrm{C}$, exposed to for three weeks. Take the number of induced shoots as an index, count and record the experiment results. Subculture the experiment on every 7 days.

\section{Sprout growth and rooting reduction}

After bud structure developed completely, put the explants into shoot elongation medium (MS with $0.35 \mathrm{mg} / \mathrm{L} \mathrm{BA}$ ), $28{ }^{\circ} \mathrm{C}$, photoperiod $16 / 8$, for 3-4 weeks. Cut off the bud with the length of $2-3 \mathrm{~cm}$ from the base, and then shift it to the rooting medium (1/2 MS with $0.5 \mathrm{mg} / \mathrm{L}$ IBA). When it grow lots of root, transferred it into the soil of the greenhouse.

\section{Statistical analysis}

The experiments were based on a completely randomized design (CRD). Each treatment had three replicates with 20 to 50 explants. The data on various parameters were subjected to one-way Analysis of Variance (ANOVA) using SPSS ver 17(SPSS Inc, Chicago, USA) and means was subjected to Ducan's multiple range test at $\mathrm{p}=0.05$.

\section{Results}

\section{Difference between two germination way}

Suitable explant is the foundation of the construction of plant regeneration system. Generally, in the process of plant tissue culture, low differentiated young meristem should be selected as starting regenerated explant. This is because the lower the degree of differentiation of tissue cells, the more likely it is to induce embryonic cells of cellular totipotency. Experiment result showed that processes of the seed germination and castor embryo germination had great difference (table1).

Embryo germination time is shorter, usually 4-5 days, with better synchronicity. Seed germination needs a longer time, generally more than 7 days, the maximum time around $18 \mathrm{~d}$. Synchronicity is not so good, which is not conducive to the implementation of the experiment. A certain concentration of BA has certain inhibition on the germination of seeds and embryo, especially for the growth of roots (fig1). Relatively, embryo germination is better for the interception of the late explant and synchronous experiment.

Table 1 Results of germination between varieties

\begin{tabular}{cccc}
\hline Germination way & BA concentration(mg/L) & Days of & Synchronism \\
\hline seed & 0 & $7-14$ & bad \\
seed & 0.2 & $7-18$ & bad \\
seed & 0.5 & $10-18$ & bad \\
embryo & 0 & $4-5$ & good \\
embryo & 0.2 & $4-5$ & good \\
embryo & 0.5 & $4-7$ & fair \\
\hline
\end{tabular}




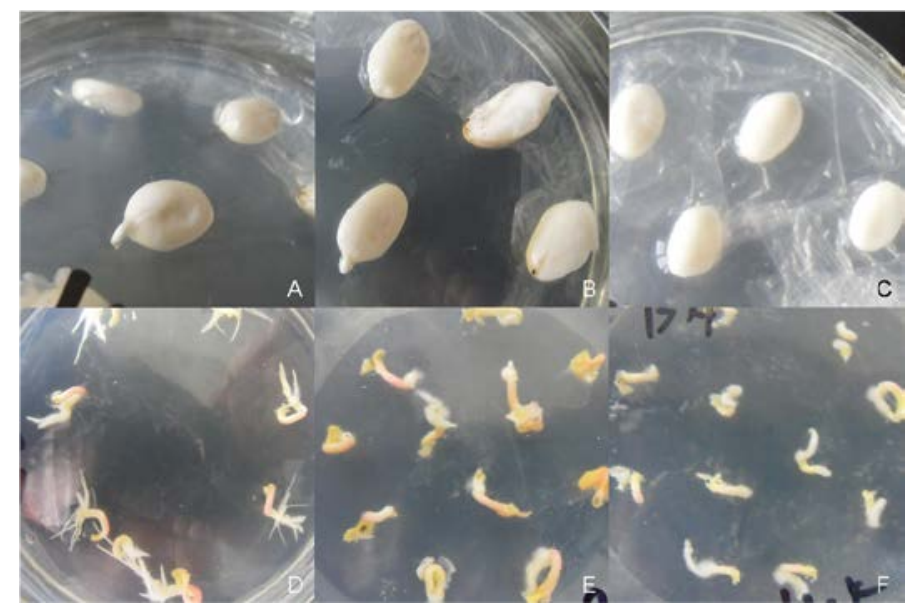

Fig.1 A,B,C are the seeds cultured for $5 \mathrm{~d}$ in the culture medium containing $0,0.2,0.5 \mathrm{mg} / \mathrm{L}$ BA; D,E,F are the embryos cultured for $5 \mathrm{~d}$ in the culture medium containing $0,0.2,0.5 \mathrm{mg} / \mathrm{L} \mathrm{BA}$

\section{Stress difference of explant}

Table 2 Stress difference of explants

\begin{tabular}{cccccc}
\hline \multirow{2}{*}{ Germination way } & $\begin{array}{c}\text { Kinds of } \\
\text { explants }\end{array}$ & \multicolumn{3}{c}{ No. of Stress explants } & \multirow{2}{*}{$\begin{array}{c}\text { Frequency of } \\
\text { Stress explants (\%) }\end{array}$} \\
\cline { 3 - 5 } & compact & $\begin{array}{c}\text { Grown } \\
\text { compact }\end{array}$ & Colorless loose & \\
\hline seed & $\begin{array}{c}\text { cotyledonary } \\
\text { node }\end{array}$ & $72 \mathrm{c}$ & 51 & 45 & $56.0 \mathrm{c}$ \\
seed & hypocotyl & $0 \mathrm{e}$ & 18 & 105 & $41.0 \mathrm{~d}$ \\
seed & cotyledon & $15 \mathrm{~d}$ & 0 & 0 & $11.6 \mathrm{e}$ \\
embryo & embryonic tips & $169 \mathrm{a}$ & 45 & 0 & $71.3 \mathrm{a}$ \\
embryo & hypocotyl & $95 \mathrm{~b}$ & 81 & 23 & $66.3 \mathrm{~b}$ \\
\hline
\end{tabular}

Experiment results showed that the stress differentiation difference of different explants is obvious (Table2). For the 2 kinds of explant, taken from embryo germination way, efficiency of producing stress is higher. The differentiation of embryonic tip explant can reach more than $70 \%$. For the 3 kinds of explant, taken from seed germination way, efficiency of producing stress is lower, only the cotyledon energy-saving around 50\%; the cotyledon explants hardly appear stress differentiation. Stress differentiation is different, which can be divided as green compact, browns firming loose, white compact (colorless) (fig2). Pale green compact model, after the late train, bud primordium is rich, the late after induction can grow new buds structure, and bud number according to the bud primordium situation is slightly different. Browns compact type after subsequent cultivation, can produce a few bud primordium, most of the cells continue to go brown until late necrosis; Late white loose breed many callus, with few sprouts growing. Finally, green compact type of embryonic was selected as the optimal explant in this experiment for it is the most easy to induce. After 5 days' preincubation, differentiate tissue was used for subsequent bud induction experiments. 


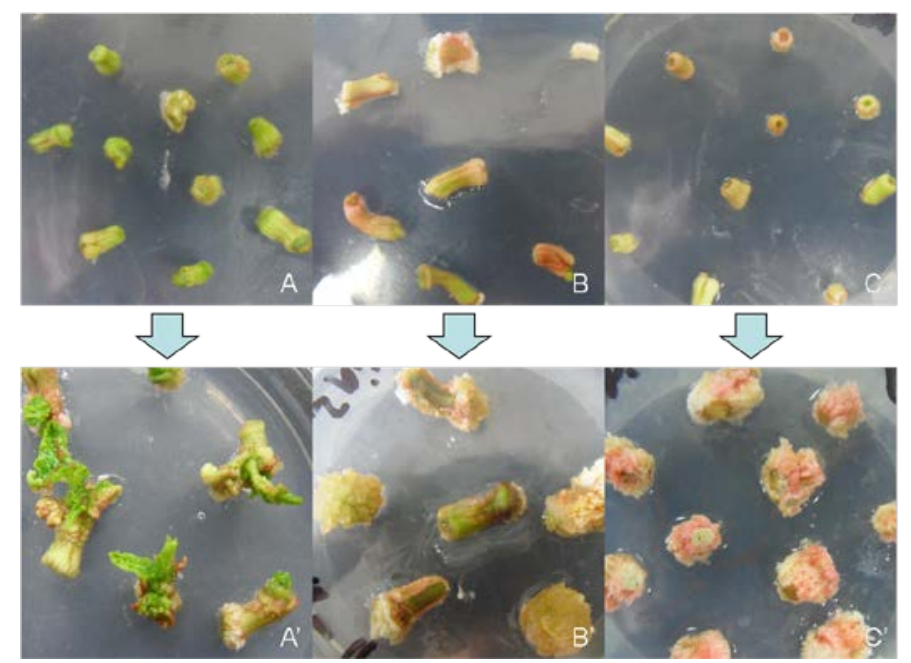

Fig.2 Difference of explants development. A, A': Green compact organization form Embryo tips; B, B': Brown compact organization from cotyledon nodes; C, C': Colorless loose organization from embryo axis Shoot induction results

Table 3 Optimization of conditions for shoot induction

\begin{tabular}{|c|c|c|c|c|c|c|}
\hline \multirow{2}{*}{$\begin{array}{l}\text { No. of } \\
\text { explants }\end{array}$} & \multicolumn{3}{|c|}{ cytokinin(mg/L) } & \multirow{2}{*}{$\begin{array}{c}\text { No. of } \\
\text { explants } \\
\text { with shoots }\end{array}$} & \multirow{2}{*}{$\begin{array}{c}\text { Frequency of } \\
\text { explants producing } \\
\text { shoots (\%) }\end{array}$} & \multirow{2}{*}{$\begin{array}{l}\text { Max No. of shoots } \\
\text { per explant }\end{array}$} \\
\hline & BA & TDZ & $\mathrm{ZT}$ & & & \\
\hline 150 & 0.2 & - & - & 95 & $63.3 \mathrm{~g}$ & 8 \\
\hline 150 & 0.35 & - & - & 121 & $80.7 a$ & 12 \\
\hline 150 & 0.5 & - & - & 96 & $64.0 \mathrm{f}$ & 8 \\
\hline 150 & 1 & - & - & 89 & $59.3 \mathrm{~h}$ & 15 \\
\hline 150 & - & 0.05 & - & 46 & $30.7 \mathrm{t}$ & 12 \\
\hline 150 & - & 0.1 & - & 48 & $32.0 \mathrm{~s}$ & 11 \\
\hline 150 & - & 0.2 & - & 26 & $17.3 \mathrm{z}$ & 11 \\
\hline 150 & - & 0.4 & - & 6 & $4.0-$ & 14 \\
\hline 150 & - & - & 4 & 56 & 37.3o & 5 \\
\hline 150 & - & - & 6 & 55 & $36.7 p$ & 6 \\
\hline 150 & - & - & 8 & 78 & $52.0 \mathrm{k}$ & 6 \\
\hline
\end{tabular}

Experiment results shows the effects of different cytokinins on bud induction are greatly different. BA processed explant will bud on the basis of increasing the meristem budding. A single explant budding number can grow more than ten shoots; for TDZ treated explant, shoots relatively concentrated on the morphological upper end. Single explant budding more intensive, and bud structure often turned out abnormal condition; ZT treated explant bud induction effect is poorer, single explant buddings are relatively less (fig3).

Statistical results show that (Table3), with the density of mitogen increased, the budding rate increased at first then decreased. BA is best; For TDZ, although single explant budding number up to 28 , but average budding rate is only around $30 \%$. Experiment also found that adding proper IBA could promote effect to bud induction. In the end we choose $0.35 \mathrm{mg} / \mathrm{L} \mathrm{BA}, 0.25 \mathrm{mg} / \mathrm{L}$ IBA MS culture medium as best bud induction medium.

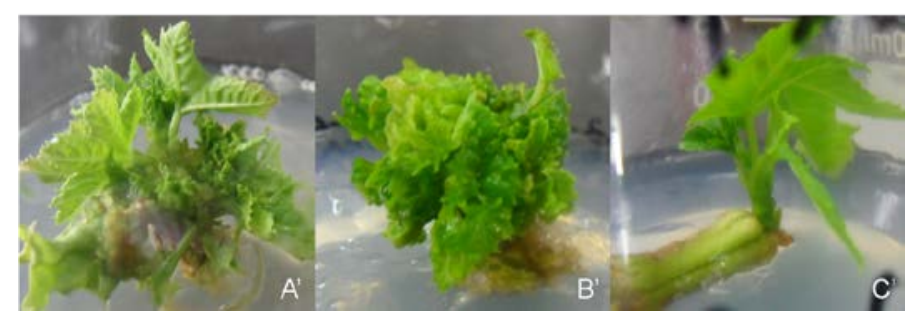

Fig.3. Induction effects of different cytokinin. A': Bud structure induced by BA and the developmental state; B': Bud structure induced by TDZ and the developmental state; C': Bud structure induced by ZT and the developmental state. 


\section{Budding and rooting induction}

Budding results show that even a single explant can induce many shoot, among which only 3-4 can extend to $2-3 \mathrm{~cm}$. this may be the key problem restricted regeneration rate of castor. The problem may be caused by under nutrition or apical dominance. Moreover, this problem should be taken as a key point for subsequent research.

It's easy for bud to root. Generally speaking, the bud will get bushy root in about 14 days. Then the bud will become a complete regeneration plant.

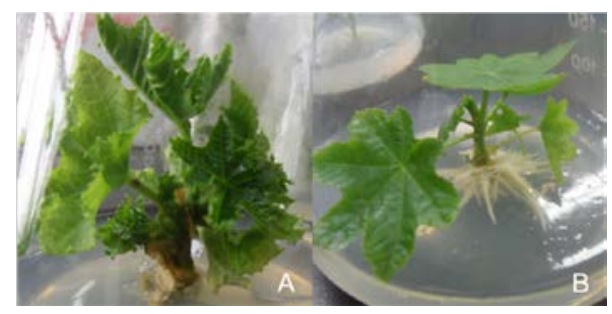

Fig.4 A: Shoot elongation culture; B: Root induction culture.

\section{Summary}

Through the selection of explants, optimization of bud induction conditions, castor regeneration system was constructed in this research, while embryo was used as explants. Regeneration plants were obtained. The comprehensive regeneration efficiency was $68.3 \%$ and the regeneration cycle was 60-70 days.

\section{References}

[1] Liv S. Severino, Dick L. Auld, Baldanzi M. 2012. A review on the challenges for increased production of castor. Agronomy Journal 104:853-880

[2] Ogunniyi D.S. 2006. Castor oil: A vital industrial raw material. Bioresource Technology 97: 1086-1091

[3] Sujatha M. and Reddy T.P. 1998. Differential cytokinin effects on the stimulation in vitro shoot proliferation from meristematic explants of castor (Ricinus communis, L.). Plant Cell Reports 17:561-566

[4] Sujatha M., Sailaja M. 2005. Stable genetic transformation of castor (Ricinus communis L.) via Agrobacterium tumefaciens-mediated gene transfer using embryo axes from mature seeds. Plant Cell Rep 23:803-10

[5] Sailaja M., Tarakeswari M., Sujatha M. 2008. Stable genetic transformation of castor (Ricinus communis L.) via particle gun-mediated gene transfer using embryo axes from mature seeds. Plant Cell Rep 27:1509-1519

[6] Ahn Y.J., Vang L., McKeon T.A., Chen G.C. 2007. High-frequency plant regeneration through adventitious shoot formation in castor (Ricinus communis L.). In Vitro Cell Dev Biol Plant 43:9-15 